Reprinted from Journal of Counseling and Development, Winter, Vol. 87 p. 108-116 (C) (2009) The American Counseling Association. Reprinted with permission. No further reproduction authorized without written permission from the American Counseling Association

\title{
Diffusion of Innovation Theory: A Bridge for the Research-Practice Gap in Counseling
}

\author{
Christine E. Murray
}

This article presents a diffusion of innovation theory-based framework for addressing the gap between research and practice in the counseling profession. The author describes the nature of the research-practice gap and presents an overview of diffusion of innovation theory. On the basis of the application of several major postulates of diffusion of innovation theory to the research-practice gap, several theory-based research practices and questions are proposed.

$$
\begin{aligned}
& \text { Getting a new idea adopted, even when it has obvious } \\
& \text { advantages, is difficult. } \\
& \text {-Everett M. Rogers (2003, p. 1) }
\end{aligned}
$$

Counseling researchers face the challenge of translating their findings into meaningful strategies for practice. Scholars have identified a major gap between research findings and clinical practice (Froehle \& Rominger, 1993; Martin \& Martin, 1989; Proctor, 2004; Rawson, Marinelli-Casey, \& Ling, 2002; D. I. Williams \& Irving, 1999). This gap reflects the tendency for many research findings to go unused, perhaps even unnoticed, by practitioners. Given that counseling is an applied behavioral science, it is especially imperative for knowledge to be developed not just for its own sake but also for the benefit of practicing counselors and the clients they serve. Thus, scholars have struggled with the issue of how to make counseling research become more relevant to practice (Anderson \& Heppner, 1986; Bradley, Sexton, \& Smith, 2005; Heppner et al., 1992; Hoshmand, 1994; Howard, 1985; Lundervold \& Belwood, 2000).

In this article, I present a theoretical framework for addressing this challenge. Diffusion of innovation theory (Rogers, 2003) describes the process through which new innovations and ideas become diffused and adopted within wider social networks. Diffusion of innovation theory has been studied and applied in a vast array of academic disciplines, including communication, marketing, and public health (Moseley, 2004; Rogers, 2004), to help researchers and program developers understand the process through which new ideas and technologies become translated into widespread practice. The purpose of this article is to present the application of diffusion of innovation theory to conceptualize the research-practice gap in the counseling profession. In the remainder of this article, I describe (a) the gap between research and practice in the counseling profession; (b) an overview of diffusion of innovation theory; and (c) an application of diffusion of innovation theory to counseling research, including theorybased research practices and questions.

\section{The Research-Practice Gap in Counseling}

Evidence-based counseling practices are necessary to establish the credibility and effectiveness of counseling interventions (Bradley et al., 2005), and many external funding agencies have begun to mandate an increased use of evidence-based practices (Rawson et al., 2002). Researchers have demonstrated the effectiveness and efficacy of many counseling-related practices (Proctor, 2004). For decades, however, the counseling profession has demonstrated a chasm between the knowledge developed by researchers and the practices used by clinicians. Despite the long-standing ideal for counselors to be scientistpractitioners, this "ideal has been poorly approximated in practice” (Howard, 1985, p. 539).

Both researchers and practitioners may experience frustration resulting from this gap. Researchers often complain that practicing counselors dismiss their research findings (Martin \& Martin, 1989), whereas counselors may view research findings as irrelevant (Howard, 1985), conflicting (Martin \& Martin, 1989), and inadequate to address the complex needs of their clients (Howard, 1985). The consequences of the research-practice gap for clients can be significant. According to Proctor (2004),

\footnotetext{
the gap between the availability and actual use of evidencebased treatments remains wide and persistent. . . This gap compromises the quality of care and threatens professionals' abilities to achieve their goals of reducing disparities in health, family well-being, and individual functioning in society. Failure to use research-based knowledge may prove costly and harmful, leading to overuse of unhelpful care, underuse of effective care, and errors in execution. (pp. 227-228)
}

\section{Proposed Reasons for the Research-Practice Gap}

How did the gap between research and practice become so significant? Scholars have placed blame for the widening gap (Dearing, 2004) on research practices, clinician attitudes,

Christine E. Murray, Department of Counseling and Educational Development, The University of North Carolina at Greensboro. Correspondence concerning this article should be addressed to Christine E. Murray, Department of Counseling and Educational Development, The University of North Carolina at Greensboro, 228 Curry Building, PO Box 26170, Greensboro, NC 27402 (e-mail: cemurray@uncg.edu).

(C) 2009 by the American Counseling Association. All rights reserved. 
counselor training deficiencies, philosophical differences, and characteristics of the relationships between researchers and clinicians. Several common research practices may contribute to the research-practice gap. First, many researchers use highly sophisticated statistical analysis procedures, and they often do not describe these procedures in language that would be understood by counselors who lack the requisite training in statistics (Bangert \& Baumberger, 2005). Second, theory-based research concepts are often ill defined and lack conceptual clarity so as to permit practical application (D. I. Williams \& Irving, 1999). In addition, researchers often do not report and interpret effect sizes, which would in part demonstrate the clinical significance of their research findings (Bangert \& Baumberger, 2005). An overreliance on quantitative methods that focus on group effects may also be less relevant to clinicians, who are privy to the extreme individual variances in human behaviors (Bangert \& Baumberger, 2005). Such research approaches often do not adequately reflect the nuances of clinical practice (Martin \& Martin, 1989). Finally, pervasive methodological limitations common to social science research also limit the practical application of research findings (Fong \& Malone, 1994).

Clinicians may hold attitudes that run contrary to a merging of research and practice. For a variety of reasons, many practitioners choose not to read scholarly publications (Froehle \& Rominger, 1993; Howard, 1985). In a related issue, many practicing counselors develop beliefs that research findings are not relevant or influential in their work (Howard, 1985; Martin \& Martin, 1989). Practitioners often ascribe special fondness to their own theories and beliefs about counseling, such that many practitioners become personally invested in their ideas and do not give them up easily, even in light of contradictory research findings (D. I. Williams \& Irving, 1999). According to D. I. Williams and Irving (1999), "such is the personal commitment and personal belief in the rightness of what therapists are doing that to challenge their position is to challenge them personally" (p. 373). This premise suggests that the personal meanings that clinicians ascribe to their beliefs and practices are more salient to them than are research findings.

Other scholars proposed that counselor educators do not provide adequate training to produce clinicians who are competent to use research findings (Martin \& Martin, 1989). According to Anderson and Heppner (1986), many counseling students do not receive sufficient training in research methodologies that would enable them to understand research studies. Indeed, Bangert and Baumberger (2005) concluded, on the basis of their findings from a recent methodological review of research articles published in the Journal of Counseling \& Development (JCD) from 1990 to 2001, that "many ACA [American Counseling Association] members will most likely find it difficult to comprehend and evaluate the usefulness of much of the research published by JCD" (p. 486). Beyond limited knowledge about research methodologies, few clinicians are trained in how to translate research findings into clinical practices (Martin \& Martin, 1989). Heppner et al. (1992) also wrote that counseling clinics housed within academic units are often underused in their research potential. The implicit message that counselors-in-training may receive is that research-occurring in the offices of faculty members - and practice - occurring in training clinics - are separate, unrelated entities.

Philosophical differences between researchers and clinicians may lead members of each group to devalue the contributions of the other group (Rawson et al., 2002; D. I. Williams \& Irving, 1999). According to Heppner et al. (1992),

scientists and practitioners are growing apart as they work in increasingly different spheres of interest and use substantially different tools in their work, and they are becoming less able to communicate with each other on the major issues that might promote their compatibility. The differences in attitudes toward the work of psychology and the anguish of trying to reconcile the needs that press on scientists and practitioners on a daily basis have left both with little energy to rediscover the old bonds of partnership and recreate a common ground for growth. (p. 110)

Also, researchers and clinicians may hold different assumptions about the nature of human development, problem causality, and client resourcefulness (Howard, 1985).

Finally, one of the most commonly cited reasons for the research-practice gap involves an inadequate relationship between researchers and clinicians for effectively disseminating research findings. Perhaps most significant is a tendency for researchers and practitioners not to value relationships with one another through their work (Froehle \& Rominger, 1993). Communication between these groups is often minimal (Martin \& Martin, 1989). Limited coordination often exists between researchers and practitioners, who work in different environments with separate needs and demands (Rawson et al., 2002). Even when there is communication between the two groups, they often lack constructive dialogue (Rawson et al., 2002).

\section{Previously Proposed Solutions to the Research- Practice Gap}

In light of the suggested reasons for the research-practice gap in counseling, a variety of solutions have been put forth to lessen the gap. These include the following: (a) Training programs should enhance counseling graduate students' training in research and statistics (Bangert \& Baumberger, 2005; Heppner et al., 1992); (b) educators should provide students with training in strategies for translating research findings into practice (Anderson \& Heppner, 1986; L. M. Williams, Patterson, \& Miller, 2005); (c) training programs should provide opportunities for students to receive hands-on experience with integrating research and clinical practice (Heppner et al., 1992; Hoshmand, 1994); (d) professional organizations should develop increased opportunities for professional dialogue between researchers and practitioners (Heppner et al., 1992; Martin \& Martin, 1989); (e) counselors should use the ACA 
Practice Research Network, which was established to create an association of clinicians to work with researchers to enhance the feasibility of research on the counseling process (Bradley et al., 2005); (f) researchers should provide clear, understandable descriptions of their research methodologies and statistical analyses (Bangert \& Baumberger, 2005); (g) researchers should demonstrate an increased use of "practitionerfriendly" research methodologies, particularly single-case research designs (Bangert \& Baumberger, 2005; Lundervold \& Belwood, 2000); and (h) scholarly journals should publish articles that are relevant to practice (Anderson \& Heppner, 1986; Heppner et al., 1992).

Clearly, much work is needed to merge counseling research with practice. Although the proposed solutions described previously have merit, they lack a theoretical foundation. A theoretical foundation provides a conceptual framework and practical guidance to researchers and clinicians as they attempt to merge distinct, yet both valuable, bodies of knowledgethose of empirical research findings and clinical wisdom. A useful theoretical framework is diffusion of innovation theory, which I describe in the following sections.

\section{Overview of Diffusion of Innovation Theory}

Diffusion of innovation theory describes the process through which new ideas, practices, or technologies are spread into a social system (Rogers, 2003). Everett M. Rogers (2003) was the most prominent developer of diffusion of innovation theory. His book, Diffusion of Innovations, was first published in 1962 and is now in its fifth edition. Formalized research on the diffusion of innovations began in 1943 with a study by Bryce Ryan and Neal Gross, from the field of rural sociology, on the diffusion of hybrid corn in Iowa (Rogers, 2003). Diffusion of innovation theory has since spread to many different fields, and thousands of studies support its tenets (Rogers, 2003, 2004). The academic disciplines in which the theory has been applied include anthropology, communication, geography, sociology, marketing, political science, public health, and economics (Moseley, 2004; Rogers, 2004).

Diffusion of innovation theory holds that innovation diffusion is "a general process, not bound by the type of innovation studied, by who the adopters [are], or by place or culture" (Rogers, 2004, p. 16), such that the process through which an innovation becomes diffused has universal applications to all fields that develop innovations. Diffusion is defined as "the process in which an innovation is communicated through certain channels over time among the members of a social system" (Rogers, 2003, p. 5). An innovation is defined as "an idea, practice, or object that is perceived as new by an individual or other unit of adoption" (Rogers, 2003, p. 12). Examples of innovations in the counseling profession include new and revised counseling techniques, theories, practice materials, assessment instruments, and technologies (e.g., practice management software).
The end results of diffusion are adoption, implementation, and institutionalization. An individual or organization (a) adopts an innovation upon the decision to acquire the innovation, (b) implements the innovation by putting it into practice and testing it, and (c) institutionalizes an innovation by supporting it fully and incorporating it into typical practice routines (Dusenbury \& Hansen, 2004; Oldenburg, Sallis, Ffrench, \& Owen, 1999). The term adoption is used throughout the rest of this article to refer to these end results of the diffusion process. The term potential adopters refers to individuals and/or organizations that are part of the social system in which an innovation is being diffused. This term refers primarily to practicing counselors in this article.

Rogers (2003) asserted that there are four main elements in the diffusion process: (a) the innovation, (b) the communication channels through which the innovation is diffused, (c) time, and (d) the social system. These elements are discussed as they apply to the counseling profession in the next section. Diffusion researchers across many academic disciplines have identified a consistent process through which innovations are diffused into social systems (Rogers, 2003). There is generally a period of slow growth, followed by more rapid expansion, followed ultimately by a plateau or another slow growth period (Rogers, 2003). Different characteristics of the innovation, communication channels, and social system are likely to have varying influences at different times throughout the diffusion process (Rogers, 2004). Because unique diffusion strategies are required as the stages of the diffusion process progress, researchers can benefit from a more in-depth understanding of the diffusion process to assist them in translating their research and innovative programs into practice.

\section{Applications of Diffusion of Innovation Theory to Counseling Research}

According to Rogers (2003), "diffusion research has a pragmatic appeal in getting research results utilized. ... The diffusion approach helps connect research-based innovations with the potential users of such innovations in a knowledge-utilization process" (pp. 104-105). In this section, I expand on nine of the major tenets of diffusion of innovation theory (Rogers, 2003) and address the implications of each postulate for the research-practice gap in counseling. For each postulate, I propose a set of diffusion of innovation theory-based research practices to bridge the research-practice gap in counseling and a set of related research questions to examine the diffusion of research in the counseling profession.

Postulate 1: There Are Five Primary Characteristics of Innovations That Influence Their Rates of

Diffusion: Relative Advantage, Complexity,

Compatibility, Trialability, and Observability

The most significant characteristics determining the rate of adoption include the innovation's perceived relative advantage over previous ideas, its complexity or ease of comprehen- 
sion, its compatibility with the potential adopter's values and needs, its trialability (i.e., its ability to be tested by the potential adopter), and its observability (i.e., the visibility of its results; Budman, Portnoy, \& Villapiano, 2003; Greenhalgh, Robert, MacFarlane, Bate, \& Kyriakidou, 2004; Rogers, 2003; Sanson-Fisher, 2004). Potential adopters' perceptions of an innovation's characteristics are more important than are objective measures of them (Rogers, 2003).

The powerful influence of these characteristics validates the importance of counseling researchers considering carefully the types of innovations they will develop and study. Because of the important role of potential adopters' perceptions of innovations in their adoption decisions, "active, face-to-face interchange between researchers and practitioners is critical" (Proctor, 2004, p. 233). Accordingly, Dearing (2004) suggested that researchers should select research topics through communication with practitioners and other stakeholders. Such researcher-practitioner dialogue helps researchers develop an understanding of the needs and values of practitioners. This dialogue also will help to ensure that the innovations researchers study meet the five characteristics described previously in a way that is meaningful to clinicians. In addition, the manner in which researchers communicate information about their innovations and research findings should be made more clear and relevant to practitioners (Bangert \& Baumberger, 2005; Proctor, 2004).

\section{Research practices}

1. Researchers develop and/or examine clinical practices and programs that have distinct advantages over other practices.

2. Researchers develop understanding of practitioners' needs and values prior to conducting research.

3 . Researchers describe innovations in sufficient detail-especially regarding their relative advantage, complexity, compatibility, trialability, and observability—so that potential adopters can make informed adoption decisions.

Research questions

1. How do counseling professionals perceive existing innovations regarding their relative advantage, complexity, compatibility, trialability, and observability?

2. Are innovations studied in counseling journals (e.g., $J C D$ and Counselor Education and Supervision) described in sufficient detail as to permit program replication/evaluation by potential adopters?

3. What are the characteristics of counseling innovations that have achieved widespread adoption in the field?

\section{Postulate 2: Communication Channels Play an Important Role in the Diffusion Process}

Even if an innovation demonstrates the aforementioned characteristics, it will never be adopted if it does not reach its intended audience. Therefore, the communication channels through which an innovation is diffused play a significant role in the diffusion process (Rogers, 2003). According to Rogers (2002), "most individuals evaluate an innovation, not on the basis of scientific research by experts, but through the subjective evaluations of near-peers who have already adopted the innovation" (p. 990). The two primary types of communication channels are mass media channels and interpersonal channels. Although mass media channels allow for more widespread dissemination of information, interpersonal channels are more influential on decision making (Rogers, 2003). Interpersonal influences can either speed up or slow down the diffusion process (Dearing, 2004). The most significant application of this postulate for the research-practice gap in counseling lies in the implication that publication in peer-reviewed journals (a mass media channel) is not sufficient for an innovation to be diffused. As stated earlier, many practicing counselors do not read scholarly journals (Froehle \& Rominger, 1993; Howard, 1985). Diffusion of innovation theory holds that even counselors who read about innovations in scholarly journals are unlikely to actually adopt an innovation on the basis of that reading alone (Rogers, 2003). Because publication in scholarly journals is a relatively ineffective strategy for affecting clinical practice, researchers should develop and use other interpersonal channels for communicating with practitioners about their innovations and research findings.

\section{Research practices}

1. Researchers use a variety of communication strategies to disseminate their findings to practitioners and other researchers. Beyond publication in peer-reviewed journals, such strategies may include presentations at professional conferences (especially conferences that draw large numbers of clinicians), public service announcements, Web sites, research reviews in clinicianoriented publications, and personal communication with decision makers in counseling organizations.

2. Researchers study the communication channels within the profession to determine which ones reach the highest numbers of clinicians.

Research questions

1. Which communication channels are most likely to reach key decision makers within clinical counseling organizations?

2. How did counselors first hear about previous innovations that they adopted?

3. Which communication channels were most persuasive in encouraging practicing counselors to adopt prior innovations?

\section{Postulate 3: The Social Context Influences a Potential Adopter's Decision}

The social context refers to the social network surrounding a potential adopter, opinion leaders within that network, and organizational characteristics (Greenhalgh et al., 2004; Rogers, 2003; Valente, 1996). Potential adopters' decisions about whether to adopt an innovation are influenced by the opinions 
of others within their social network (Dearing, 2004; Rogers, 2003; Valente, 1996). Once an innovation becomes adopted by some individuals within a social network, it becomes increasingly likely that other members of that social network will also adopt the innovation, especially if the early adopters hold positive opinions of the innovation (Greenhalgh et al., 2004; Rogers, 2003; Valente, 1996).

All members of a social network are not equally influential in affecting other members' decisions. Opinion leaders are individuals within a social network who strongly influence other members (Dearing, 2004; Rogers, 2003; Valente, 1996). Opinion leaders do not necessarily hold official leadership positions, but rather their influence often stems from informal leadership roles that are ascribed to them by peers (Rogers, 2003). Rogers (2003) characterized opinion leaders as having more exposure to people outside the immediate social network, greater accessibility to others, higher levels of innovativeness, and somewhat higher socioeconomic statuses than do others in the social network. Dearing (2004) stated that "opinion leader approval is crucial for introducing new ideas into communication networks and lending those ideas credibility" (p. 27). In addition to the social network, certain organizational characteristics render it more or less likely that an innovation will be adopted. Greenhalgh et al. (2004) wrote about a number of aspects of the organizational climate that influence adoption rates, including the size of the organization, the availability of resources, the organizational hierarchy, the organization's capacity for new knowledge, and the general climate of openness to change.

Counseling researchers would benefit from increased attention to the social context as they plan and carry out their research. If counseling researchers develop innovations that hold minimal appeal to members of practitioner social networks, these innovations are unlikely to be used and diffused. Counseling researchers would benefit from an increased understanding of opinion leaders within the counseling profession. Finally, counseling researchers should never underestimate the power of organizational structures that exist within clinical counseling settings. Characteristics such as high clinical turnover rates, limited availability of financial resources, and high client caseloads may hinder the diffusion process.

\section{Research practices}

1. Researchers develop and study innovative programs that could reasonably be incorporated into existing clinical counseling organizational structures.

2. Researchers make active efforts to inform opinion leaders within professional social networks of their research findings.

3. Researchers seek the input of opinion leaders in the early stages of research planning.

4. Researchers present findings in such a way that deemphasizes their expert authority and emphasizes the value of those findings for practitioners.

\section{Research questions}

1. Who are opinion leaders within the profession?

2. What are the characteristics of clinical counseling organizations that are most likely to adopt new innovations?

3. What types of resources are required most often of clinical counseling organizations in the process of adopting new evidence-based practices?

\section{Postulate 4: Potential Adopters Are More Likely to Adopt an Innovation When They Perceive a Change Agent to Be Homophilous (Similar) to Them as Compared With When They Perceive a Change Agent to Be Heterophilous (Different) From Them}

Rogers (2003) wrote, "Most individuals do not evaluate an innovation on the basis of scientific studies. ... Instead, most people depend mainly upon a subjective evaluation of an innovation that is conveyed to them from other individuals like themselves [italics added]" (pp. 18-19). This postulate suggests that people are more likely to adopt innovations that are presented to them by individuals whom they perceive to be similar to them. Rawson et al. (2002) also emphasized that the relationship between the individuals who propose the innovation and the individuals who will adopt it plays an important role in determining how potential adopters will perceive the innovation. Diffusion of innovation theory suggests that the optimal relationship is based on mutual respect, similar value systems, and open communication.

The gap between research and practice in the counseling profession may reflect growing differences between researchers and practitioners in the field (Heppner et al., 1992). Diffusion of innovation theory implies that counseling practitioners who perceive researchers to be dissimilar to them with respect to their values, knowledge base, and clinical experience are unlikely to welcome researcher-developed innovations. The theory suggests that if researchers and practitioners continue to perceive themselves to be operating in distinct spheres, the split between the two groups will become wider. Researchers can work to enhance their similarity to practitioners by conducting clinical work, drawing on their clinical training as they conduct research studies, and maintaining positive relationships with practitioners.

\section{Research practices}

1. Researchers actively conduct ongoing clinical work. They make efforts to "think like clinicians" while they plan, carry out, and report their research.

2. Researchers maintain collegial professional relationships with full-time practitioners who work in the area of their research.

3. Researchers stay abreast of clinical trends.

Research questions

1. To what extent do practicing counselors view themselves as being similar or dissimilar to counseling researchers? 
2. To what extent do counseling researchers view themselves as being similar or dissimilar to practicing counselors?

3. On which characteristics do practicing counselors and counseling researchers perceive themselves to be most similar and dissimilar?

4. To what extent do researchers consider clinical relevance as they plan and carry out their research?

5. What are the most effective strategies for fostering collegial relationships between researchers and practitioners?

\section{Postulate 5: The Consequences of an Innovation} Can Be Anticipated and/or Unanticipated, Desirable and/or Undesirable, and Direct and/or Indirect

Research studies frequently do not capture the full range of consequences of the innovations under investigation (Rogers, 2003). Most innovation studies use quantitative methodologies and focus only on outcomes that are demonstrated at a single point in time (Meyer, 2004). In part, because of the common practice of researchers selecting outcome measures prior to the beginning of a study, it becomes especially likely that researchers will not account for the unanticipated, undesirable, and indirect consequences of the innovations they study (Rogers, 2003). Nevertheless, practitioners are likely to encounter a wide range of consequences for the innovations they adopt. Although some undesirable consequences of counseling innovations are likely to be predictable to clinicians, unforeseeable undesirable consequences may lead an adopter to abandon an innovation that he or she has adopted. For this reason, counseling researchers should examine an extensive range of consequences for the innovations they develop and study. Meyer recommended that researchers use broader methodologies - including panel studies, point-of-adoption studies, longitudinal research, archival records, quasi-experimental designs, and qualitative methods - for this purpose.

\section{Research practices}

1. Researchers make efforts to measure any undesirable, unanticipated, and indirect consequences of the innovations they develop and study.

2. Researchers conduct follow-up studies to examine long-term consequences.

\section{Research questions}

1. What are the most effective strategies for researchers to use to identify and address the undesirable, unanticipated, and indirect consequences of their innovations?

2. How do practitioners evaluate the possible consequences of an innovation they are considering adopting?

\section{Postulate 6: Reinvention Often Occurs as Innovations Are Diffused}

The study of innovation reinvention is a recent development in diffusion of innovation theory (Rogers, 2004). Reinvention refers to "the degree to which an innovation is changed or modified by a user in the process of adoption and implementation" (Rogers, 2003 , p. 17). Although some researchers believe that programs should be implemented exactly as their developers and evaluators designed them, previous research suggests that it is more important for programs to be adaptable to meet local needs (Dusenbury \& Hansen, 2004). In fact, innovations that are more amenable to reinvention are adopted more quickly and are more likely to be sustained over time (Rogers, 2003). This postulate suggests that counseling researchers should develop and study innovations that incorporate the flexibility for practitioners to adapt the innovations on the basis of the needs of their surrounding communities. In addition, researchers should study the effectiveness of modifiable programs in their various reinvented forms.

\section{Research practices}

1. Researchers develop and study innovations that are able to be reinvented by practitioners as they are adopted locally.

2. Researchers study the reinvention process as it applies to counseling interventions.

3. Researchers provide strategies for practitioners to evaluate the effectiveness of innovations they adopt and reinvent.

Research questions

1. To what extent does modifying an innovation to meet local needs enhance or detract from its effectiveness?

2. Are practitioners more accepting of innovations and research findings that they perceive to be able to be adapted to meet local needs?

3. How confident are practitioners that they can modify researcher-developed innovations?

Postulate 7: Preventive Innovations Are Often Slow to Be Diffused Because of Their Unclear Relative Advantage

There has been a growing interest in preventive interventions within the counseling profession (Albee, 1995; Murray, 2005). Diffusion of innovation theory holds that preventive innovations are especially unlikely to be diffused quickly and easily (Rogers, 2002, 2003). Because their outcomes are often delayed and not clearly visible (i.e., the desired outcomes are the absence of the targeted behavior or event), preventive innovations often demonstrate an uncertain relative advantage over other practices, leading to slower rates of adoption than do other types of innovations (Rogers, 2003). Rogers (2002) stressed the importance of increasing the relative advantage of preventive innovations to enhance their diffusion (e.g., by reducing their costs and increasing their immediate benefits). He also recommended that multiple strategies be used to diffuse the innovations within relevant social networks. Research on preventive counseling innovations, therefore, demands rigorous attention to diffusion strategies. 
Research practices

1. Researchers examine directly the relative advantages of the preventive interventions they develop by comparing their programs with other practices.

2. Researchers measure both short- and long-term outcome variables related to preventive innovations.

Research questions

1. What are the most effective strategies for promoting preventive programs in the counseling profession?

2. How can the immediate benefits of preventive innovations be maximized?

\section{Postulate 8: Potential Adopters Go Through a Thorough Decision-Making Process Prior to Deciding Whether to Adopt or Reject an Innovation}

The decision whether to adopt an innovation often requires time, energy, and careful consideration on behalf of the potential adopter (Rogers, 2003). Researchers who develop innovations often underestimate the extensive decision-making process involved in making these decisions (Diamond, 1996). Rogers (2003) suggested that there are five phases in the adoption decision-making process: (a) gaining knowledge about the innovation, (b) being persuaded to form an opinion about it, (c) making a decision whether to adopt or reject it, (d) implementing or putting into use the innovation, and (e) receiving confirmation or reinforcement of the decision made. Psychological processes that may arise during the decision-making process include anxiety related to uncertainty, resistance to change, and a sense of loss over abandoning previous ideas or practices (Diamond, 1996; Rogers, 2003).

Counseling researchers should be prepared to provide clinicians with adequate time and information needed to make adoption decisions. Information about the innovation's trialability and flexibility to reinvention can be particularly useful in the decision-making process. It is also important for counseling researchers to refrain from making negative judgments about practitioners (e.g., they are slow, apathetic, or too set in their ways) who choose not to adopt an innovation (Rogers, 2003). Rather, counseling researchers would benefit from learning more about the reasons of practitioners who have decided not to adopt an innovation, given that this information can assist researchers in developing and studying future innovations.

\section{Research practices}

1. Researchers provide practitioners with detailed information about the innovations they develop and study to permit practitioners to make informed decisions.

2. Researchers acknowledge that all innovations are not appropriate for all practitioners and the organizations in which they practice.

Research questions

1. What information is most significant to practitioners as they decide whether to adopt an innovation?
2. Which sources of information are practicing counselors most likely to consult as they consider whether to adopt an innovation?

\section{Postulate 9: There Are Five Categories Into Which Adopters Fall on the Basis of Their Rates of Adoption: Innovators, Early Adopters, Early Majority, Late Majority, and Laggards}

Individuals vary in their willingness to accept new ideas and change (Valente, 1996). Characteristics of individuals that influence their willingness to adopt innovations include the following: personality characteristics (e.g., tolerance for ambiguity and learning style), motivation to change, their perceived needs, the meaning they attribute to the innovation, and the type and amount of information they have available about the innovation (Greenhalgh et al., 2004). Rogers (2003) classified adopters into the following five categories on the basis of their rates of adoption: (a) innovators, who are among the first $2.5 \%$ in the population to adopt the innovation and demonstrate an adventurous, cosmopolite nature; (b) early adopters, who fall into the next $13.5 \%$ of adopters and who are integrated closely into the social network and are often opinion leaders; (c) the early majority, who are the next $34 \%$ of adopters and are described as deliberate followers; (d) the late majority, the next 34\% who are often skeptical of the innovation at first but eventually succumb to peer pressure; and (e) laggards, who are the final $16 \%$ and who tend to be more traditional and isolated compared with earlier adopters. Individuals who are among the last to adopt an innovation often exhibit the longest decision-making processes prior to deciding to adopt the innovation (Rogers, 2003).

The primary application of this postulate to the researchpractice gap is the reminder to researchers that the diffusion process takes time. Counseling researchers must bear in mind that all members of a social network will not change immediately as a result of an innovative research finding or practice. In fact, those practitioners who are early in the innovation process are "often thought of as being either elite or eccentric" (Dusenbury \& Hansen, 2004, p. 55). Diffusion of innovation theory suggests that the diffusion process takes off once approximately $10 \%$ to $20 \%$ of the members of a population have adopted an innovation (Rogers, 2003). This suggests that counseling researchers should use a slow, steady process for diffusing their innovations and not give up when ideas do not spread widely and immediately.

\section{Research practices}

1. Researchers accept that practitioners vary in their willingness to adopt innovations. They do not pressure practitioners to adopt innovations before they are prepared to do so.

2. Researchers provide sufficient information to practitioners to reduce potential adopters' anxiety associated with the uncertainty involved in adopting an innovation. 


\section{Research questions}

1. Within the counseling profession, what are the demographic and professional background characteristics of people in each of the five adopter categories?

2. Does the diffusion of innovations in the counseling profession follow the same S-shaped curve as has been demonstrated in other fields?

\section{Conclusion}

Bridges can be built between research and practice. Nevertheless, it is unlikely that research and clinical practice will ever become fully merged. According to Martin and Martin (1989),

research results will never totally guide clinical practice; the number of variables is far greater than could ever be realistically examined. However, research can be informative and can help guide choices. Using research findings with sound clinical judgment helps counselors more ably assist their clients, which is the common goal among researchers and clinicians alike. (pp. 491-492)

On the basis of diffusion of innovation theory, the ultimate goal for counseling researchers is for their research findings to be disseminated and adopted by practicing counselors if and when these practicing counselors believe that research findings are relevant and useful to their work.

Although both researchers and practitioners share accountability for bridging the research-practice gap in the counseling profession (Howard, 1985), researchers bear responsibility for taking the following steps to ensure that their work is clinically useful. First, researchers should study relevant topics and innovations. Second, researchers should use appropriate communication channels for sharing their findings with practitioners. Third, researchers should consider the consequences of their innovative ideas and practices. Fourth, researchers should provide flexibility for their innovations to be reinvented by practitioners. Fifth, researchers should examine and study the diffusion process within the counseling profession to learn about how practitioners make their decisions about adopting innovations. Finally, researchers should respect and seek out the knowledge of practitioners. According to diffusion of innovation theory, these steps will help to ensure that research findings have an impact on practicing counselors and the clients they serve.

\section{References}

Albee, G. W. (1995). Counselling and primary prevention. Counselling Psychology Quarterly, 8, 205-211.

Anderson, W. P., \& Heppner, P. P. (1986). Counselor applications of research findings to practice: Learning to stay current. Journal of Counseling and Development, 65, 152-155.

Bangert, A. W., \& Baumberger, J. P. (2005). Research and statistical techniques used in the Journal of Counseling \& Development: 1990-2001. Journal of Counseling \& Development, 83, 480-487.
Bradley, L. J., Sexton, T. L., \& Smith, H. B. (2005). The American Counseling Association Practice Research Network (ACA-PRN): A new research tool. Journal of Counseling \& Development, 83, 488-491.

Budman, S. H., Portnoy, D., \& Villapiano, A. J. (2003). How to get technological innovation used in behavioral healthcare: Build it and they still might not come. Psychotherapy: Theory, Research, Practice, Training, 40, 45-54.

Dearing, J. W. (2004). Improving the state of health programming by using diffusion theory. Journal of Health Communication, 9, 21-36.

Diamond, M. A. (1996). Innovation and diffusion of technology: A human process. Consulting Psychology Journal: Practice and Research, 48, 221-229.

Dusenbury, L., \& Hansen, W. B. (2004). Pursuing the course from research to practice. Prevention Science, 5, 55-59.

Fong, M. L., \& Malone, C. M. (1994). Defeating ourselves: Common errors in counseling research. Counselor Education and Supervision, 33, 356-362.

Froehle, T. C., \& Rominger, R. L. (1993). Directions in consultation research: Bridging the gap between science and practice. Journal of Counseling \& Development, 71, 693-699.

Greenhalgh, T., Robert, G., MacFarlane, F., Bate, P., \& Kyriakidou, O. (2004). Diffusion of innovations in service organizations: Systematic review and recommendations. The Millbank Quarterly, 82, 581-629.

Heppner, P. P., Carter, J. A., Claiborn, C. D., Brooks, L., Gelso, C. J., Fassinger, R. E., et al. (1992). A proposal to integrate science and practice in counseling psychology. The Counseling Psychologist, 20, 107-122.

Hoshmand, L. T. (1994). Supervision of predoctoral graduate research: A practice-oriented approach. The Counseling Psychologist, 22, 147-161.

Howard, G. S. (1985). Can research in the human sciences become more relevant to practice? Journal of Counseling and Development, 63, 539-544.

Lundervold, D. A., \& Belwood, M. F. (2000). The best kept secret in counseling: Single-case $(N=1)$ experimental designs. Journal of Counseling \& Development, 78, 92-102.

Martin, D., \& Martin, M. (1989). Bridging the gap between research and practice. Journal of Counseling and Development, 67, 491-492.

Meyer, G. (2004). Diffusion methodology: Time to innovate? Journal of Health Communication, 9, 59-69.

Moseley, S. F. (2004). Everett Rogers' diffusion of innovations theory: Its utility and value in public health. Journal of Health Communication, 9, 149-151.

Murray, C. E. (2005). Prevention work: A professional responsibility for marriage and family counselors. The Family Journal, 13, 27-34.

Oldenburg, B. F., Sallis, J. F., Ffrench, M. L., \& Owen, N. (1999). Health promotion research and the diffusion and institutionalization of interventions. Health Education Research, 14, 121-130. 
Proctor, E. K. (2004). Leverage points for the implementation of evidence-based practice. Brief Treatment and Crisis Intervention, 4, 227-242.

Rawson, R. A., Marinelli-Casey, P., \& Ling, W. (2002). Dancing with strangers: Will U.S. substance abuse practice and research organizations build mutually productive relationships? Addictive Behaviors, 27, 941-949.

Rogers, E. M. (2002). Diffusion of preventive innovations. Addictive Behaviors, 27, 989-993.

Rogers, E. M. (2003). Diffusion of innovations (5th ed.). New York: Free Press.
Rogers, E. M. (2004). A prospective and retrospective look at the Diffusion Model. Journal of Health Communication, 9, 13-19. Sanson-Fisher, R. W. (2004). Diffusion of innovation theory for clinical change. The Medical Journal of Australia, 180, S55-S66.

Valente, T. W. (1996). Social network thresholds in the diffusion of innovations. Social Networks, 18, 69-89.

Williams, D. I., \& Irving, J. A. (1999). Why are therapists indifferent to research? British Journal of Guidance and Counselling, 27, 367-376.

Williams, L. M., Patterson, J. E., \& Miller, R. B. (2005). Panning for gold: A clinician's guide to using research. Journal of Marital and Family Therapy, 32, 17-32. 
Copyright of Journal of Counseling \& Development is the property of American Counseling Association and its content may not be copied or emailed to multiple sites or posted to a listserv without the copyright holder's express written permission. However, users may print, download, or email articles for individual use. 